\title{
Gootitsismist BALTI VARAUUSAEGSES AJALOOKIRJUTUSES
}

\author{
Janet Laidla
}

Mitmete moodsate ajaloofilosoofide arvates tegelevad ajaloolased pigem mineviku loomise kui selle uurimise või ülestähendamisega. Arvatavalt on lihtsam luua selliste ajalooperioodide ajalugu, mis on allikatega hästi kaetud. Euroopa varakeskaja ajalugu seda ei olnud ning kimbatus vaevas 17. sajandi Eesti- ja Liivimaa kroonikuid Moritz Brandist, Thomas Hiärni, Gustav von Lodet ja David Wernerit ning Christian Kelchi, kes soovisid kirjutada nn täispikki kroonikaid, mis algaksid kõige vanemast ajast ning jõuaksid autori kaasaega välja.

Nimetatud kroonikate varakeskaja kirjeldusele ei ole Balti vanema kroonikakirjutuse uurimisloos varem tähelepanu pööratud, sest tegemist on selle perioodi osas ebausaldusväärsetest allikatest kokku kirjutatud kompilatsioonidega, mille allikaline väärtus on praktiliselt olematu. Nii suhtus 19. sajandil Riia Ajaloo ja Muinsuste Seltsi president Georg Berkholz saksa kaupmeeste tuleku eelsete sündmuste kirjeldustesse väga kriitiliselt. ${ }^{1}$ Baltisaksa ajaloolaste jaoks oli oluline säilitada arusaam saksa kaupmeeste tulekust kui ajaloolise aja algusest Vana-Liivimaal, mis iseenesest on samuti osaliselt mütologiseeritud ning kinnistunud varauusajal. ${ }^{2} \mathrm{Ka} 20$. sajandi esimesel poolel käsikirja jäänud Balti vanema ajalookirjutuse autor Lemmit Mark nimetab perioodi käsitlust fantastikaks, mis tugineb Skandinaavia allikate müütilistele teadetele ja näiteks Moritz Brandise kroonika puhul peaks kuuluma ajalookirjutuse paberikorvi. ${ }^{3}$ Hilisematest uurijatest seob

\footnotetext{
Artikkel on valminud Eesti Teadusfondi grandi nr 8205 toel.

${ }^{1}$ Georg Berkholz, "Renner's livländische Chronik", Mittheilungen aus dem Gebiete der Geschichte Liv-, Ehst- und Kurlands, 12 (1880), 159-215 (178-180).

2 Vt Paul Johansen, "Die Legende von der Aufsegelung Livlands durch Bremer Kaufleute", Sonderdruck aus Europa und Übersee: Festschrift für Egmont Zechlin (Hamburg: Hans Bredov-Institut, 1961); Marek Tamm, "Liivimaa leiutamine: uue kristliku koloonia kuvandi loomine 13. sajandi esimesel poolel", Akadeemia, 2 (2012), 195-229.

3 Lemmit Mark, Eesti vanema historiograafia ajalugu, II, käsikiri Tartu Ülikooli Raamatukogu käsikirjade ja haruldaste raamatute osakonnas [edaspidi TÜR KHO], f. 75, s. 10, 1. 237. Ka mujal keeldusid ajaloolased alates 19. sajandi teadusliku ajaloo tekkimisest sellist "müütilist", "legendaarset" ja "sümboolset" sündmustekirjeldust ajaloo hulka
} 
Gottfried Etzold Brandise kujutatud suhteid Skandinaaviaga varakeskajal Rootsi valitsusega varauusajal. ${ }^{4}$

Gustav von Lode ja David Werneri kroonikat peavad Leonid Arbusow ja Lemmit Mark väga Taani-meelseks ning arvavad, et autor on üritanud tõestada, et enne saksa kaupmeeste tulekut oli piirkond Taani võimu all. Varasema ajaloo käsitlust peab Mark puhtaks väljamõeldiseks. ${ }^{5}$ Ka Thomas Hiärni ja Christian Kelchi kroonikate varakeskaega kirjeldavasse osasse suhtutakse kriitiliselt. ${ }^{6}$ Noore Eesti Vabariigi ajaloolasi paelus kahtlemata muistne iseseisvusaeg ja kindlasti ka Henriku kroonika, kuid arheoloogiliste leidude ja dokumentide-kroonikateadetega kinnitamata teabesse suhtusid nemadki ettevaatlikkusega.

Varauusaegsele keskaja nägemusele on mujal hakatud üha rohkem tähelepanu pöörama nii ajalookirjutuse kui ka näiteks riigi ja rahvuse loomise vaatepunktist. Näiteks Frank L. Borchardti teos keskendub renessansiaegsetele germaani mineviku kirjeldustele. ${ }^{7}$ Teoses on nimetatud arvukalt perioodi autoreid ning Borchardti on huvitanud nii nende allikad kui ka näiteks rahva päritolu ning keisririiki puudutavad müüdid. Soome ajaloolane Erkki Lehtinen on uurinud, kuidas on varauusajal nähtud Soome riigi algust. ${ }^{8}$ Tähelepanu on pööratud ka varakeskaja ajaloonägemusele ning analüüsitud kroonikate autorite allikate ajaloopilti ja sünnikonteksti. ${ }^{9}$ Ideeajaloolisest vaatepunktist on kroonikate varakeskaja kirjelduste

arvamast. Kriitika läks nii kaugele, et kesk- ja varauusaegseid kroonikaid anti välja ilma esimeste osadeta, põhjendusega, et need on liiga fantastilised, et toimetamine aega väärt oleks. Kroonikas peeti oluliseks vaid seda osa, mis vastas Ranke-järgsele ajalookirjutuse standardile, vt Frank L. Borchardt, German antiquity in Renaissance myth (Baltimore, London: John Hopkins Press, 1971), 3-5.

4 Gottfried Etzold, "Die Geschichtsschreibung der polnisch-schwedischen Zeit", Geschichte der deutschbaltischen Geschichtsschreibung, hrsg. von Georg von Rauch (Köln-Wien: Böhlau, 1986), 43-62 (50).

5 Leonid Arbusow, "Die handschriftliche Überlieferung des 'Chronicon Livoniae' Heinrichs von Lettland", Latvias Universitātis Raksti, 15 (1926), 189-341 (330); Mark, Eesti vanema historiograafia ajalugu, II, 269-270.

6 Hiärni kohta Mark, Eesti vanema historiograafia ajalugu, II, 259-260, 276.

7 Borchardt, German antiquity.

8 Erkki Lehtinen, Suomen varhaishistorian ja ristiretkikauden kuvasta uskonpuhdistusja suurvalta-aikana, Historiallisia tutkimuksia, LXXXV (Jyväskylä, 1968).

9 Vt nt The uses of the past in the early Middle Ages, ed. by Yitzhak Hen and Matthew Innes (Cambridge: Cambridge University Press, 200o). Ja mitte ainult, varakeskaja ajaloo kasutamisest räägitakse ka näiteks 19. sajandi kontekstis, vt nt The uses of the Middle Ages in modern European states: history, nationhood and the search for origins, ed. by R. J. W. Evans and Guy P. Marchal (Basingstoke: Palgrave Macmillan, 2011); Derek Fewster, Visions of past glory, nationalism and the construction of early Finnish history (Helsinki: Finnish Literature Society, 2006). 
näol tegemist kahtlemata huvitava nähtusega. Kroonikute sellisel lähenemisviisil oli olemas oma eesmärk, käsitlus tugines allikatele ning allikatest saadud teave oli vormistatud kronoloogiliseks narratiiviks.

Rahvaste, riikide, valitsejate suguvõsade ja institutsioonide päritolu müütiline konstrueerimine on läbi aegade olnud oluline nii päevapoliitikas kui ka laiemalt rahvusliku identiteedi määratlemisel. Gootitsism oli üks päritolu konstrueerimise avaldumisvorme, mida iseloomustas riigi, valitsejadünastia ja/või rahva päritolu seostamine gooti rahvaga. Gootitsismi ilminguid võib täheldada keskajal ja varauusajal mitmel pool Euroopas. Järgneva artikli eesmärk on lühidalt tutvustada gootitsismi kui nähtust ${ }^{10}$ ja seejärel analüüsida selle avaldumisvorme Balti varasemas ajalookirjutuses.

\section{Rahvaste päritolust Euroopas ja Rootsi gootitsismist}

Üheks levinud rahva (ka linna, riigi või valitsejate dünastia) päritolu müüdiks sai lugu Trooja sõjast ja selles ellujäänud kangelastest. Nii kirjutas Rooma poeet Publius Vergilius Maro (70-19 eKr) (varasema Kreeka traditsiooni põhjal) teose "Aeneis", kus Trooja sõjas ellujäänud nimikangelane rajas oma ema, jumalanna Venuse käsul Itaaliasse Rooma riigi näol Uue Trooja. ${ }^{11}$ Prantsusmaal on frangid troojalasi oma esivanemateks pidanud juba Merovingide ajast peale, ${ }^{12}$ kuid varauusajal seati see müüt kahtluse alla. Humanist ja õpetlane Beatus Rhenanus väitis ühena esimestest, et prantslaste Trooja päritolu on legend ja tegelikult vallutasid Prantsusmaa alad hoopis germaani hõimud, kuid Prantsusmaa haritlased ei tervitanud seda teooriat. Mõned, näiteks Jean Bodin, olid nõus suhtuma Trooja legendi suure kahtlusega, kuid eitasid frankide germaani päritolu. ${ }^{13} 16$. sajandi teisel poolel hülgasid õpetlased troojalaste legendi ja asendasid selle allikate põhjal koostatud frangi päritolu teooriaga, ${ }^{14}$ ent pärast 1600 . aastat ilmus Trooja legend ametlikku ajalookirjutusse tagasi. 17. sajandi kuningliku propaganda jaoks oli nimelt päevapoliitiliselt oluline väide, et frangid ei

\footnotetext{
10 Lisaks sellele, et puudub kaasaegne ülevaatlik käsitlus Balti vanemast ajalookirjutusest, ei ole eesti keeles ilmunud ka ülevaatlikku teost maailma ajalookirjutuse ajaloost.

11 Ants Oras, "Saateks", Publius Vergilius Maro, Aeneis, tlk Ants Oras (Lund: Eesti Kirjanike Kooperatiiv, 1975), 5-12 (6).

12 George Huppert, The idea of perfect history: historical erudition and historical philosophy in Renaissance France (Urbana, Chicago, London, 1970), 72. Pikemalt nii eelpoolviidatud teoses kui ka George Huppert, "The Trojan Franks and their critics", Studies in the Renaissance, 12 (1965), 227-241.

13 Huppert, The idea of perfect history, 78-79.

14 Ibid., 73-75.
} 
saa olla germaani rahvas. ${ }^{15}$ Üks 17. sajandi hinnatumaid ajaloolasi François de Mézeray (1610-83) lahendas probleemi, esitades lugejale mõlemad versioonid - nii keskaegse legendi kui ka selle humanistliku kriitika. Veel 1714. aastal saadeti Nicolas Fréret Bastille'sse, kuna tal oli jultumust väita, et frangid olid germaanlased. ${ }^{16}$

Inglased pidasid end samuti keskaegseid kroonikaid (Monmouthi Geoffrey ja "Brut") järgides troojalastest pärinevaks. ${ }^{17}$ Legendi kritiseeris itaalia päritolu humanist Polydore Vergil, kes seetõttu kohalike ajalookirjutajatega konflikti sattus. Teravalt kritiseerisid Vergilit Arturi-legendi purustamise pärast näiteks John Leland ja John Bale. ${ }^{18}$ Siiski leidus ka inglaste hulgas neid, kes suhtusid Inglismaa varasesse minevikku kriitiliselt. ${ }^{19}$ Teiste hulgas eitas inglaste Trooja päritolu katoliiklasest dissident Richard Verstegan. ${ }^{20}$

Skandinaavia rahvaste esiisaks peeti gooti rahvast, kelle päritolu oli 6. sajandi autor Jordanes viinud Noa järglaste Gogi ja Magogini. ${ }^{21}$ Rootslased otsisid oma rahvale väärikaid esivanemaid ning leidsid need antiikautorite poolt kirjeldatud gootide näol. Tähelepanuväärne verstapost gootitsismi kasutamises poliitilise argumendina oli 1434. aasta Baseli kontsiil, kus Rootsi saadik Nicolaus Ragvaldi pidas kõne Rootsist kui gootide sünnimaast, milline kuulsusrikas minevik pidanuks õigustama ka Rootsi riigi väärikamat positsiooni kirikukongressil. ${ }^{22}$ Gooti päritolu muutus oluliseks poliitilises filosoofias, kus riigi väärikust ja vägevust hinnati teiste tegurite

\footnotetext{
Huppert, The idea of perfect history, 73-75.

6 Nt Huppert, "The Trojan Franks", 227.

17 Nt Denys Hay, Annalists and historians: Western historiography from the eighth to the eighteenth centuries (London, Methuen, [New York]: Harper \& Row, 1977), 59-60; Arthur B. Ferguson, "John Twyne: a Tudor humanist and the problem of legend", The Journal of British Studies, 9:1 (1969), 24-44 (26).

18 Polydore Vergili kohta nt Denys Hay, Polydore Vergil: Renaissance historian and man of letters (Oxford: Clarendon Press, 1952), konflikti kohta lk 158-16o.

19 Kõik kohalikud ei astunud Trooja legendi kaitseks välja, vt nt Ferguson, "John Twyne".

20 Graham Parry, The trophies of time: English antiquarians of the seventeenth century (Oxford, New York: Oxford University Press, 2007; esmatrükk 1995), 51.

${ }^{21}$ Jordanese ja gootide ajaloo kohta vt Walter A. Goffart, The narrators of barbarian history (A.D. 550-80o): Jordanes, Gregory of Tours, Bede, and Paul the Deacon (Princeton, NJ: Princeton University Press, 1988); Josef Svennung, Jordanes und Scandia: Kritisch-exegetische Studien (Stockholm: Almqvist \& Wiksell, 1967); Josef Svennung, "Jordanes und die gotische Stammsage", Studia Gotica: Die eisenzeitlichen Verbindungen zwischen Schweden und Südosteuropa, hrsg. von Ulf Erik Hagberg (Stockholm: Almqvist \& Wiksell, 1972) 20-56.

22 Sten Lindroth, "Der Gotizismus und seine Bedeutung in der schwedischen Wissenschaft", Studia Gotica, 12-19 (14).
} 
hulgas ka selle vanusega. ${ }^{23}$ Suurema hoo sai gootitsism sisse 16. sajandil. ${ }^{24}$ Liikumine tungis ka kunsti ja kuningas Erik XIV ajal valmistati mitmeid seinavaipu, mis kirjeldasid gootide ajalugu. ${ }^{25}$ Gootitsism sai ajalookirjutuses ja kultuurielus mõjuva positsiooni, oli seotud populaarse antikvaarse liikumisega (ruunide ja matmispaikade uurimine) ning seda kasutati poliitilistel eesmärkidel. Oluline oli liikumine ka 17. sajandil, eriti alates Gustav II Adolfi valitsusajast. ${ }^{26}$

Oluline osa oli gootitsismi poliitilisel suunal mängida Rootsi ja Taani vahelises sulesõjas. 1514. aastal andsid Iodocus Badius Ascensius ja Christiern Pedersen välja Saxo Grammaticuse (u 1150-1220) "Gesta Danorumi". ${ }^{27}$ Juba kirjutamise ajal oli Saxo töö olnud patriootilise suunitlusega, selle eesmärk oli tõsta taanlaste eneseteadvust. ${ }^{28}$ Luterliku Rootsi vastulause tuli kahelt Roomas pagenduses viibivalt katoliiklikult vaimulikult - vendadelt Johannes ja Olaus Magnuselt. ${ }^{29}$ Magnuste teoseid nimetas rootsi kultuuriajaloolane Sten Lindroth 16. sajandi patriootilise romantika

\footnotetext{
${ }_{23}$ Inken Schmidt-Voges, De antiqua claritate et clara antiquitate Gothorum: Gotizismus als Identitätsmodell im frühneuzeitlichen Schweden, Imaginatio borealis, 4 (Frankfurt am Main; New York: P. Lang, 2004), 217-218.

24 Gootitsismist Rootsis on kirjutatud mõõdukalt. Teedrajavaks võib pidada Johan Nordströmi esseesid kogumikus De yverbornes ö (Stockholm: Bonnier, 1934). Nordström kaardistab ja kirjeldab liikumist varauusajal kahes essees: "Götisk historieromantik och stormaktstidens anda" (55-76) ja "De yverbornes ö" (89-154). Lisaks nt Josef Svennung, Zur Geschichte des Goticismus, Skrifter utgivna av K. Humanistiska Vetenskapssamfundet i Uppsala, 44 (Stockholm: Almqvist \& Wiksell, 1967). Svennungi teos annab ülevaate gootitsismist üle terve Euroopa. Hea lühiülevaade gootitsismist Rootsis on Nils Erikssoni "Göticismen”, 17 uppsatser i svensk idé- och lärdomshistoria ([Uppsala]: Carmina, 1994), 35-43 või Lindrothi, "Der Gotizismus". Lisaks nt Ernst Ekman, "Gothic patriotism and Olof Rudbeck", The Journal of Modern History, 34:1 (1962), 52-63. Kristoffer Neville soovib oma hiljutises artiklis näidata, et siiani on Skandinaavia ajalookirjutuses keskendutud vaid ühele gootitsismi tahule, jättes selle laiemad mõjualad tähelepanuta, vt Kristoffer Neville, "Gothicism and early modern historical ethnography", Journal of the History of Ideas, 70:2 (2009), 213-234 (214). Soomes nt A. A. A. Laitinen, Michael Wexionius-Gyldenstolpe (Helsinki, 1912); Erkki Urpilainen, Algot Scarin ja gööttiläisen historiankirjoituksen mureneminen Ruotsissa 17oo-luvun alkupuolella (Helsingi: SHS, 1993).

25 Schmidt-Voges, De antiqua claritate, 238-241.

26 Sten Lindroth, Svensk lärdomshistoria: Stormaktstiden (Stockholm: Norstedt, 1989; esmatrükk 1975), 249-256. Põhjalik ja kaasaegne käsitlus gootitsismi tähendusest varauusaegses Rootsis vt Schmidt-Voges, De antiqua claritate.

27 Woldemar Westergaard, "Danish history and Danish historians", The Journal of Modern History, 24:2 (1952), 167-180 (168); Kurt Johannesson, The Renaissance of the Goths in sixteenth century, trans. and ed. by James Larson (Berkeley, Los Angeles, Oxford: University of California Press, 1991), 103.

28 Westergaard, "Danish history", 168.

29 Johannesson, The Renaissance of the Goths, 216-217.
} 
kulminatsiooniks. ${ }^{30}$ Rootsi luterlikud kuningad toetasid vendade Magnuste teoseid ja nende populaarsus levis üle Euroopa. ${ }^{31}$ Vastuseks Magnuste ajaloole lasi Taani kuningas Christian IV omalt poolt lausa neljal ajaloolasel asuda kirjutama Taani riigi ajalugu ladina keeles (tuntumad kaks nende hulgas olid hollandlased Johann Isaac Pontanus ja Johannes Meursius). ${ }^{32}$

Rootsis tegeleti gootitsismiga jõudsalt edasi. Jacobus Gislonis üritas gooti ajalugu ühildada maailmakroonikaga, mis oli ühtlasi esimene katse Rootsis kirjutada universaalajalugu. ${ }^{33}$ Tartu õuekohtu assessor ja Vasula mõisaomanik Georg Stiernhielm uuris gootide algkeelt ja kirjutas vastulause Philipp Cluverile, kes pidas Preisimaad gootide kodumaaks. ${ }^{34}$ Stiernhielm seostas hüperborealased põhja rahvastega ja arvas, et Uppsala paganlik tempel on seotud Apolloga ("De hyperboreis", 1685). ${ }^{35}$

Sellest arenesid edasi veelgi suurejoonelisemad ideed. Tõenäoliselt kõige väärikama ja fantaasiarikkama pildi Rootsi minevikust maalis Olof Rudbeck, kelle järgi sarnast ajalookirjutust on nimetatud rudbekianismiks. $\mathrm{Ta}$ arendas edasi Johannes Bureuse, Georg Stiernhielmi ja Olaus Vereliuse ideid ning tema arvates asus Platoni kadunud Atlantis Skandinaavia poolsaarel. Rudbeck pakkus oma väite kinnituseks tõestusmaterjali nii ajaloo kui ka loodusteaduste vallast. Teos tekitas mitmesuguseid (kohati vastakaid) arvamusi nii Rootsis kui ka mujal Euroopas. ${ }^{36}$ Osaliselt võib siin kindlasti näha püüet tuua Euroopa tsivilisatsiooni häll barbaarsele Põhjamaale. Sten Lindroth tõdeb, et kuigi tegemist oli oma hüpoteeside poolest julge ja fantaasiarikka käsitlusega, olid selle argumendid leidnud tõendusmaterjali tolle aja autoriteetsetest allikatest ning kogu traditsioon oli seotud eelpoolmainitud Euroopas levinud mõtteviisiga, mille juured ulatuvad hilisantiiki. ${ }^{37}$

Näited Euroopa ajalookirjutusest tõendavad, et Balti kroonikate varakeskaja käsitluses ei olnud midagi erakordset. Pigem oleks olnud

\footnotetext{
30 Sten Lindroth, Svensk lärdomshistoria: Medeltiden/Reformationstiden (Södertälje, 1989; esmatrükk 1975), 288.

31 Vt Johannesson, The Renaissance of the Goths.

32 Vt pikemalt Karen Skovgaard-Pedersen, Historiography at the court of Christian IV (1588-1648): studies in the Latin histories of Denmark by Johannes Pontanus and Johannes Meursius (Copenhagen: Museum Tusculanum Press; University of Copenhagen, 2002).

33 Teos koosneb Johannes Magnuse kroonikast mõjutatud kronoloogilistest tabelitest, Lindroth, Svensk lärdomshistoria: Medeltiden/Reformationstiden, 308.

34 Lindroth, Svensk Lärdomshistoria: Stormaktstiden, 267-274.

35 Ibid., 269.

36 Nt Ibid., 284-305; Ekman, "Gothic patriotism”; põhjalik ja äärmiselt huvitav käsitlus on Gunnar Erikssoni The Atlantic vision: Olaus Rudbeck and Baroque science (Canton, MA: Science History Publications, 1994).

37 Lindroth, "Der Gotizismus", 12-13.
} 
märkimisväärne, kui nii autoriteetsete allikate, nagu seda olid tol ajal Saxo ja vennad Magnused, olemasolul ja kättesaadavusel, oleksid autorid jätnud selle osa ajaloost käsitlemata. Allikakriitika tänapäevases mõistes oli alles kujunemas ning selle põhitõed ei olnud Balti kroonikutele, kes olid oma olemuselt siiski mitte professionaalsed, vaid pigem harrastusajaloolased, omaks saanud.

\section{Gootitsismi ilmingutest Balti vanemas ajalookirjutuses}

Ühena esimestest kirjeldas Skandinaaviaga seotud müütilist varakeskaega Johann Renner ${ }^{38}$ oma 16. sajandil kirjutatud kroonikas. Renneri kroonika ilmus trükist alles 1876 . aasta ${ }^{39}$ Bremeni muuseumiühingu raamatukogust Dr. J. G. Kohli leitud käsikirja järgi. Enne seda olevat kroonika olnud unustatud. ${ }^{40}$ Renner kirjutas oma kroonika arvatavasti Balthasar Russowi eeskuju järgi ümber, ${ }^{41}$ kuid lisas sinna peatüki Liivimaa müütilisest esiajaloost, mida Russowi kroonikas ei olnud. 17. sajandil leidub gootitsismi elemente kõige eredamalt sissejuhatuses nimetatud neljas täispikas kroonikas. Moritz Brandise ${ }^{42}$ kroonika valmis tegelikult juba 16. sajandi viimastel aastatel. Thomas Hiärni ${ }^{43}$ ja Lode-Werneri kroonikad ${ }^{44}$ valmisid mõlemad

\footnotetext{
38 Johann Renner sündis 16. sajandi esimesel poolel Tecklenburgis Osnabrücki lähedal. Täpsemad teated tema elukäigu kohta pärinevad 1550. aastatest, mil ta oli ametnik Bremenis ja Speyeris. Ilmselt 1556. aastal tuli ta Liivimaale ja leidis teenistust Järva foogti Bernt von Schmerteni juures. 1561. aastal läks ta Saksamaale tagasi ning suri ilmselt enne sajandi lõppu, vt Richard Hausmann und Konstantin Höhlbaum, "Vorwort", Johann Renner's Livländische Historien, hrsg. von Richard Hausmann und Konstantin Höhlbaum (Göttingen: Vandenhoeck \& Ruprecht, 1876), v-vi.

39 Vt eelmist. Siin artiklis on kasutatud seda väljaannet. Mõlemal eestikeelsel trükil puudub esimene, meid huvitav osa: Johann Renner, Liivimaa ajalugu 1556-1561, tlk Ivar Leimus (Tallinn: Olion, 1995) ja teine parandatud trükk (Tallinn: Olion, 2006). 1876. aasta väljaanne ja eestikeelne väljaanne tuginevad erinevatele Renneri käsikirjadele.

40 Käsikirjas kroonikad võisid siiski varauusajal laialt levida.

41 Hausmann, Höhlbaum, "Vorwort", v-xii. Arvatavalt varasema käsikirja avastas 1934. aastal Lübecki linnaraamatukogust P. Karlstedt.

${ }_{42}$ Moritz Brandise elukäigust on teada vähe. Teame, et 1580-93 oli ta diplomaat Elert Kruse teenistuses ning seejärel Eestimaa rüütelkonna sekretär. Tema surma dateeritakse 17. sajandi esimesse kümnendisse, Etzold, "Die Geschichtsschreibung", 49-51.

43 Thomas Hiärn (ka Hiärne või Hjärne) (1638-78) oli pärit Ingerimaalt. 1654-55 õppis ta Academia Gustaviana's ning töötas hiljem Bengt Horni erasekretärina ning mitmetes riigiametites. 1670. aastal sai temast Virtsu mõisa inspektor ning sel ajal valmis ka tema Eesti-, Liivi ja Lätimaa kroonika (esmatrükk 1794). Hiärni kohta lähemalt vt Laidla, “Thomas Hiärn”, 78-84; Piret Lotman, "Thomas Hiärne - nimi Rootsi Läänemereprovintside varasest ajalookirjutusest”, Ajalookirjutaja aeg = Aetas historicorum, koost Piret Lotman (Tallinn, Eesti Rahvusraamatukogu, 2008), 114-140. 44 Lode-Werneri kroonika nime all tuntakse Loodna ja Öötla mõisa omaniku Gustav von Lode (1633-1705) ning tema laste koduõpetaja David Werneri koostöös valminud saksa- ja
} 
17. sajandi seitsmekümnendatel aastatel ning Christian Kelchi ${ }^{45}$ kroonika ilmus sajandi lõpus. Lisaks oli mitmeid lühemaid teoseid, mis samuti kirjeldasid Skandinaavia kuningate tegusid. Näiteks võib tuua Jacob Schotte kõne ${ }^{46}$ ja mõned teised 17. sajandi ja 18. sajandi alguse kroonikad. ${ }^{47}$ Varakeskaja käsitlemisest otsustas loobuda Daniel Hartnack, sest ta ei usaldanud allikaid. ${ }^{48}$

ladinakeelsest käsikirja Liivimaa ajaloost, Mark, Eesti vanema historiograafia ajalugu II, 267. Siiani ei olda päris kindlad, kas Gustav von Lode on saksakeelse originaali autor ja Werner tõlkis selle ladina keelde või oli viimase roll kroonika koostamisel suurem, vt nt Arbusow, "Die Handschriftliche", 330. Tööst on säilinud mitmeid käsikirju ning Sulev Vahtre hinnangul on kõige väärtuslikum neist Venemaa Teaduste Akadeemia Raamatukogus, mis sisaldab ainsana kõigist teadaolevatest käsikirjadest nii saksakui ka ladinakeelset teksti, vt Sulev Vahtre, "Balti kroonikate käsikirjadest Peterburi raamatukogudes”, Oppetatud Eesti Seltsi aastaraamat 2002 (Tartu, 2004), 297-306 (303). Selle artikli kirjutamisel on kasutatud ühte ladinakeelset ja kahte saksakeelset käsikirja: Epitome historica rerum, in Aestonia, Livonia, Lettia, Curlandia, atque Semgallia, tum ante, tum post natum Christum usque ad annum 1677 gestarum, cum hodierno publico harum provinciarum statu ... A Davide Wernero S.S. Cultore, nobilissimae Juventutis a Lode in aula Palensi p: $t$ : informatore, Anno MDCLXXX, TÜR KHO, mscr 171; Lode's Ehst- und Livländische Geschichte, Ajalooarhiiv [edaspidi EAA], f. 854, n. 1, s. 767 ja f. 2062, n. 1, s. 6.

45 Christian Kelch (1657-1710) oli pärit Saksamaalt Pommerist. Ta õppis Oderi-äärse Frankfurti ülikoolis mh nimeka ajaloolase Johann Friedrich Beckmanni käe all. Kelch õppis ka Rostocki ülikoolis, kust ta oli sunnitud majanduslikel põhjustel lahkuma. Kelch tuli Tallinna eesmärgiga raha teenida ning sai koduõpetaja koha praostide Andreas Forseliuse ja seejärel Reiner Broocmanni juures vastavalt Põltsamaal ja Laiusel. Hiljem töötas ta vaimulikuna Järva-Jaanis ja Tallinnas. Põhjalikuma käsitluse krooniku eluloost võib leida Rudolf Winkleri artikli originaalist või selle osalisest tõlkest Kelchi kroonika esimese osa sissejuhatuses: R. Winkler, "Beiträge zur Kentniss des Chronisten Kelch und seiner Zeit”, Beiträge zur Kunde Ehst-, Liv- und Kurlands, Bd. 5, Heft 2 (Reval: Lindfors' Erben, 1898), 111-130. Christian Kelch, Liivimaa ajalugu, tlk Ivar Leimus (Tartu: Eesti Ajalooarhiiv, 2004), v-xv

46 Jacob Schotte, Historia de Livonia, quam ... in Regia Academia Gustaviana, quae Dorpati est ad Embeccam, oratione solenni ... die 9. Martij, ... anno 1639. publice pro concione posteritati consecrabat Jacobus Scott, nob. Livonus (Dorpati: [Typ. acad.], 1639). $47 \mathrm{Nt}$ An account of Livonia; with a relation of the rise, progress, and decay of the Marian Teutonick Order. The several revolutions that have happen'd there to these present times, with the wars of Poland, Sweden and Muscovy, contending for that province (London: Peter Buck, 1701). Lode-Werneri kroonikast refereerisid varakeskaja sündmusi ka Adam Friedrich von Fischbach ja Otto Fabian von Wrangell.

48 Hartnacki teos algabki kriitikaga Olaus ja Johannes Magnuse teadete vastu ja kokkuvõtteks tõdeb autor: "Ich mag meinen wehrten Leser so ungewisse Dinge nicht vortragen / und fange daher diese Erzehlung allein von A. tausend ein hundert acht und funfftzig an / da diesem Volck zuerst der Christliche Glaube / und uns von ihnen etwas gewissere Nachricht kund worden." Daniel Hartnack, Kurtzer Entwurff Lieffländischer Geschichte (Hamburg: Conrad Neumann, 1700), Vorrede und Einleitung, pagineerimata. 
Moritz Brandise, Thomas Hiärni ja Lode-Werneri kroonikad jäid käsikirja. Brandise kroonika ei jõudnud ajaliselt väga kaugele (vaid 1238. aastani), ka Hiärni kroonika jäi lõpetamata, kuigi selle trükkimist kavandas nii autor oma eluajal kui ka raamatukaupmees Heinrich Hackelmann kohe pärast autori surma. ${ }^{49}$ Moritz Brandise ja Thomas Hiärni kroonikad trükiti 18.-19. sajandil. Brandise toimetas ja andis trükki Carl Julius Albert Paucker ning see ilmus 1842. aastal sarja "Monumenta Livoniae antiquae" III köites..$^{50}$ Thomas Hiärni kroonika on trükis ilmunud kahel korral, mõlemal juhul ebatäielikult ja mitte kõige parema käsikirja järgi. ${ }^{51}$ Vaid Kelchi kroonika esimene osa jõudis juba tema eluajal trükki ${ }^{52}$ tema kroonika järg avaldati aga samuti alles 1875 . aastal Johannes Lossiuse poolt. ${ }^{53}$

Nimetatud kroonikate valiku põhjuseks oli jaotus sajandi algusesse, keskpaika ja lõppu. Kõik hilisemad autorid tundsid Brandise tööd ja Kelch ning Lode-Werneri kroonika autor lisaks ka Thomas Hiärni kroonikat, mis laseb võrrelda, kui palju kasutati allikaid ja kui palju kirjutati ümber varem valminud kroonikaid. Viimati mainitud aspekt oli üks põhjus, miks nelja eelpoolmainitud krooniku käsitlust on võrreldud Johann Renneri kroonikaga. Renneri kroonika oli kirjutatud Saksamaal ja ilmus trükis alles 19. sajandil ning võib eeldada, et see ei mõjutanud siinset 17. sajandi ajalookirjutust.

Nelja kroonika suhtumine käsitletavasse teemasse on erinev. Moritz Brandisel algab tekst üleminekuga sellelt, kuidas kohalikud paganad olid hirmsad röövlid. Brandis kirjutab, et juba Skandinaavia ajalookirjutajad kirjeldavad, kuidas siinsed rahvad käisid laevadega Skandinaavia rannikut

49 Vt nt Laidla, "Thomas Hiärn", 82-83.

50 Moritz Brandis, Ehstländischen Ritterschafts-Secretairen, Chronik, oder älteste Livländische Geschichte nebst den ältesten Ritter-oder Lehn-Rechten ... , hrsg. von C. J. A. Paucker, Monumenta Livoniae antiquae, 3 (Riga, Leipzig: Frantzen, 1840).

51 Thomas Hiärn, Ehst-, Liv- und Lettländische Geschichte, 1, hrsg. von J. F. von Recke (Mitau: Johann Magnus Wehrt, 1794); Thomas Hiärn, Ehst-, Lyf- und Lettlaendische Geschichte, sarjas Monumenta Livoniae antiquae, 1, hrsg. von C. E. Napiersky (Riga, Dorpat, Leipzig: Eduard Frantzen's Buchhandlung, 1835); Nachtrag zu Thomae Hiaern's Ehst-, Lyf-und Lettländischer Geschichte, sarjas Monumenta Livoniae Antiquae, 2, hrsg. von C. E. Napiersky (Riga, Leipzig: Eduard Frantzen's Buchhandlung, 1839). 1835. ja 1839. aasta väljaannete tekstid on kättesaadavad Tartu Ülikooli digitaalarhiivis DSpace.

52 Liefländische Historia, oder Kurtze Beschreibung der Denkwürdigsten Kriegs- und Friedens-Geschichte Esth-Lief- und Lettlandes; Vornehmlich in sich begreiffend einen kurtzen Bericht von den Nahmen, Entheilung und Beschaffenheit der Provintz Liefland, ... Theils aus Ein- und Ausländischen Geschicht-Schreibern / ... zusammen getragen und in fünff Büchern abgefasset, von Christiano Kelchen, Pastore zu St. Johannis in Jerwen (Reval: Mehner, 1695). Siin artiklis kasutatud põhiliselt eelpool viidatud eestikeelset väljaannet.

53 Christian Kelch, Liefländische Historia: Continuation 1690 bis 1707, hrsg. von Johannes Lossius (Anstalt-Dorpat: Gläser, 1875). 
kimbutamas. Nende röövretkede vastu ehitas kuningas Siggo 2004. maailma aastal Sigtuna linna, kuid paraku see ei aidanud, sest eriti eestlased jätkasid oma röövretki ka järgnevate valitsejate ajal järgmise 400 aasta vältel. ${ }^{54}$ Brandis ei sea üldjuhul oma allikatest (siinkohal Jacob Gislonis) saadud teavet kahtluse alla ning kohalike rahvaste kommete ja uskumuste kirjeldus läheb sujuvalt üle ajaloosündmuste kirjelduseks.

Thomas Hiärn alustab peatükki hoopis teisiti. Ta nendib, et arvestades, kui paljud rahvad oma varasemast ajaloost vähe teavad, pole ime, et ka Eesti- ja Liivimaa rahvastest on vähe teateid. Rootsi, Taani ja Norra ajalookirjutajate poolt üles tähendatud vähesed teated on eriti ajaarvamise osas enne Kristuse sündi ja ka natuke hiljem, väga kahtlased. Et mitte "last koos pesuveega välja visata”, on Hiärn üritanud ajalooraamatutest usaldusväärsed teated välja noppida. Siingi esitab ta lugejale mitu versiooni, alustades Sigtuna rajamise kohta jutustavate legendidega. Esimesena toob ta ka Brandisel kirjas olnud Johannes Magnuse versiooni linna rajamisest ning sinna kõrvale Olaus Vereliuse "Hervarar Saga", mille kohaselt rajas linna keiser Augustinuse ajal Rootsi jumal Odin, keda nimetati ka Sigiks. ${ }^{55}$

Lode-Werneri kroonika autor ei ole samuti päris kindel ja alustab kahtleval toonil - "kui soovitakse autoreid uskuda". Autor kirjutab, et pea kõik ajaloolased, kes kirjutavad Eestimaa rahvast, väidavad, et nad olid jaotatud väikesteks kuningriikideks ning käisid rootslasi ja goote kimbutamas. Lode-Werner järgib kohati sõna-sõnalt Brandist, kuid mõne sõna või väljendi kohta kasutab näiteks sünonüümi (nt schützen vs bewahren und versichern). ${ }^{56}$

Christian Kelch soovib teemast kiirelt ja lühidalt üle minna Sigtunat mainimata. Ta alustab oma käsitlust vapra kuninga Bericoga (Brandisel, Hiärnil ja Lode-Werneril AM 2493, Kelchil 836 pärast veeuputust), kes vallutas mitmeid rahvaid. Kuningas Berico kirjeldus on näiteks Brandisel väga pikk ja sisaldab ka kangelase suhu pandud kõnet, mida Kelch mainib. Teiste kroonikute kirjeldused Bericost ja ka edaspidi on Brandisest oluliselt lühemad ning Lode-Werneri kroonika tekst on Brandisele kõige sarnasem. ${ }^{57}$

Võrdluseks võib tuua, et Johann Renneri käsitlus algab alles 470. aastast eKr kuningas Hadinguga. Hilisematel kroonikutel on Hadingu ajaks kirjeldatud juba mitmete Skandinaavia valitsejate teod.

\footnotetext{
54 Brandis, Chronik, 17-18.

55 Hiärn, Ehst-, Lyf- und Lettlaendische Geschichte, 50.

56 Lode's Ehst- und Livländische Geschichte, EAA, f. 2062, n. 1, s. 6, 1. 37-37p.

57 Brandis, Chronik, 18-20; Hiärn, Ehst-, Lyf- und Lettlaendische Geschichte, 50-51; Lode's Ehst- und Livländische Geschichte, EAA, f. 2062, n. 1, s. 6, 1. 38, Kelch, Liivimaa ajalugu, 31 .
} 
Varakeskaja perioodile (st kuni saksa kaupmeeste tulekuni) pühendatud mahu kindlaks määramine erinevates kroonikates on üsna keeruline ning tulemus umbkaudne. Moritz Brandise tekst näib olevat kõige pikem. Ajaloolised sündmused kuni sakslaste tulekuni võtavad enda alla osa teisest ja terve kolmanda raamatu. Pauckeri väljaandes on seda 27 lehekülge, samas tuleb märkida, et kohati on pool lehekülge täidetud Pauckeri joonealuste viidetega. Hiärni teose varakeskaegne osa näib olevat pisut lühem, see on trükis 15 lehekülge pikk ning moodustab kroonika teise raamatu. LodeWerneri kroonika on olemas vaid käsikirjas ning varakeskaegseid sündmusi on kirjeldatud kroonika teises peatükis. Tekst on mõnevõrra lühem kui Brandisel ja Hiärnil. Veelgi lühem on käsitlus Kelchi kroonikas, võttes enda alla eestikeelses väljaandes vaid neli lehekülge. Lode-Werneri ja Hiärni käsitlused on sarnased selle poolest, et mõlemad alustavad teemat uuest peatükist, Brandis tõmbab piiri Kristuse sündimise aega.

Kroonikas kirjeldatud sündmusi kokku võttes on põhimõtteliselt tegemist sajanditepikkuse Läänemere-äärsete rahvaste vastastikuste sõjakäikude kirjeldusega. Piirkonnas elavad mitmed rahvad, kelle nimetuse osas kroonikud ja nende allikad ei ole alati ühele meelele jõudnud. Seega võime lugeda eelkõige eestlaste ja liivlaste, kuralaste, rootslaste ja gootide (nii n-ö kodumaa ehk Skandinaavia gootide kui ka välismaa ehk mandri gootide) ning taanlaste tegevusest veeuputuse-järgsetest aegadest saksa kaupmeeste tulekuni.

Tegevus on lugejani toodud kronoloogiliselt valitsejate järgi ning puudutatud on reeglina vaid neid sündmusi, mis on seotud Vana-Liivimaaga. Vaid Brandis ja Hiärn on altimad tutvustama sündmusi, mis otseselt siinseid piirkondi ei puuduta. Kui Skandinaavia allikad siinseid rahvaid ei maini, tõdevad kroonikud, et kohalikest rahvastest pole jälle mõned sajandid midagi kuulda. Kõik 17. sajandi kroonikud kasutavad enne Kristuse sündi ajaarvamist maailma loomisest (anno mundi, AM) ning pärast Kristuse sündi lähevad üle ajaarvamisele pärast Kristuse sündi (anno Christi, AC). Renner ei kasuta kunagi AM, vaid ainult enne ja pärast Kristust.

Käsitluse ülesehitusel on lähtutud Skandinaavia valitsejatest. Siinsetest valitsejatest on nimepidi mainitud vaid mõningaid üksikuid. Näiteks tunneme me Kuramaa kuningat Lockerit, kes võitles Taani printsi Hadinguga. ${ }^{58}$ Brandis tutvustab nimepidi veel kahte kuralast - Amundit ja Todhot, kes olid mereröövlid, kuni Rootsi kuningas Haldanus nad vangistas. ${ }^{59}$

58 Hiärn, Ehst-, Lyf- und Lettlaendische Geschichte, 52.

59 Brandis, Chronik, 34. 
Eestlastest on esindatud nimepidi kangelane Starkotter ${ }^{60}$ ning kuna Hiärn toob lugejani lühidalt Olaf Trygvassoni saaga sündmused, siis ka selles saagas figureeriv eestlane Reäs. Lugu räägib sellest, kuidas kuningas Trygge lesk Astrid läks koos poja Oloffiga oma venda Sigurdit otsima ning langes mereröövlite küüsi. Mereröövel Klärkon müüs kuningapoja eestlasele Reäsele, kes tema eest hästi hoolitses, kuni onu Sigurd ta 977. aastal ära tundis, Venemaale kaasa viis ja seejärel temast Norra kuninga tegi. See Norra kuningas olevat esimene, kes hakkas Norras kristlikku usku levitama. ${ }^{61}$

Pikemalt on kirjeldatud, kuidas Taani kuninga poeg Frotho otsustas kuramaalased endale kuulekaks teha. Kuramaa kuningas Dorno arvas, et ta ei saa nii vägevale vaenlasele vastu, kasutas põletatud maa taktikat ning lasi oma rahval rannast kaugemale põgeneda. Ise varjus ta ühte kindlusesse, mille müürides ta kindel oli, ning panustas sellele, et Frotho ei saa kindlust kaua piirata, sest tal pole piisavalt toiduvarusid. Frotho aga teeskles põgenemist ja meelitas niimoodi kuralased linnusest välja. ${ }^{62}$ Samuti tuuakse meieni Liivimaa printsi Bicco tegevus, kelle vanemad vennad Taani kuningas Jarmerich ära tappis. Bicco seadis end aga Jarmerichi õukonnas sisse ning andis kuningale kättemaksuks halba nõu. Näiteks süüdistas ta kuningapoega Broderust selles, et too olevat oma võõrasemaga voodit jaganud. ${ }^{63}$

Kui siinkohal tuua võrdluseks samaaegne Soome ajalookirjutus, siis seal tuntakse esimesi Soome kuningaid nimepidi, kuigi nimedes ei ole alati omavahel kokkuleppele jõutud. Nii on rootsi päritolu ajaloolase Johannes Messeniuse "Soome riimkroonikas" ${ }^{64}$ kolm esimest kuningat Fornjot, Froste ja Jokull, aga anonüümses Soome kroonikas ("Chronicon Finlandiae") on mainitud esimesteks Soome kuningateks Rostiof, Fernioti ja Snio. Soome kroonika autor on oma andmed kogunud Saxo Grammaticuse, Norra avastamise loo ("Fundinn Noregr"), Snorri Sturlasoni ja Soome rahvaluule põhjal. ${ }^{65}$

Kui Kristuse sündimise ajani on valitsejate nimekiri Hiärnil ja Brandisel (ning viimase järgi ka Lode-Werneril ja Kelchil) enam-vähem sarnane,

60 Brandis, Chronik, 34; Hiärn, Ehst-, Lyf- und Lettlaendische Geschichte, 56.

61 Hiärn, Ehst-, Lyf- und Lettlaendische Geschichte, 60-61.

62 Renner, Livländische Historien, 10, Brandis, Chronik, 26-27, Hiärn, Ehst-, Lyf- und Lettlaendische Geschichte, 52-53.

63 Brandis, Chronik, 36-37; Hiärnil Bicko, Ehst-, Lyf- und Lettlaendische Geschichte, 58-59.

64 Johannes Messenius, Suomen riimikronikka, toimittaneet ja suomentaneet Harry Lönnroth ja Martti Linna (Helsinki: SKS, 2004).

65 Martti Linna, Jorma Lagerstedt ja Erkki Palmén, “Tuntematton tekijan Suomen kronikka", Suomen, Liivinmaan ja Kuurinmaan vaiheita: sekä tuntemattoman tekijän Suomen kronikka (Helsinki: SKS, 1988) 123-134. 
siis pärast seda lähevad kõik kroonikud erinevat teed pidi. Nõus ollakse, et kuningas Erik II valitses AM 3745 ja Lindorn 3796. Brandisel asus seejärel valitsema Taani kuningas Frotho III.

Hiärni huvitas rohkem kangelane Starkotter (Starchatern), keda Brandis mainis, kuid kahe krooniku arvamused tema tegevuse ajal valitsenud Taani kuningast lähevad lahku: Brandisel on see Frotho III, Hiärnil Philimer. Brandise järgi sündis kangelane Eestis, Hiärn toob ära, et Saxo on nimetanud teda eestlaseks, Johannes Magnus väidab aga, et Starkotter on pärit Rootsist Helsinglandist.$^{66}$ Hiärn kirjutab ka, et ta ei usu juttu sellest, et kangelane elas 300 aastat. Ta seletab, et tegelikult oli olemas kaks Starkotterit. Esimene oli eestlane, kuid tema poja Storwerkeri poeg oli samuti Starkotter. Kahe samanimelise kangelase tegevus on aja jooksul segunenud ning nii saadud üks üleloomulikult pika elueaga kangelane. Kui üldiselt järgib Kelch pigem Brandist kui Hiärni, siis Starkotteri osas nimetab ta kangelast olevat Helsinglandist pärit. ${ }^{67}$

Pärast Starkotterit keskendub Hiärn läbi pikema arutluskäigu erinevate rahvaste päritolule, toetudes Jordanese, Johannes Micraeliuse, Bossau Helmoldi, Bremeni Adama ja Procopiuse teostele. Varauusaegsed ajalookirjutajad pidid leidma õige tee kõikide rahvaste vahel, keda antiik- ja keskaegsed autorid on nimetanud ja kirjeldanud. Nii üritabki Hiärn selgusele jõuda, kus konkreetsed rahvad tol perioodil paikneda võisid ning kelle võimu alla jäid. Lode-Werneri kroonika aga räägib germaanlastest Tacituse ajal, toetudes nii Tacituse raamatule "Germaanlaste päritolust ja paiknemisest" kui ka Ptolemaiose teadetele.

Ka kronoloogia läheb kroonikutel paigast. Brandise järgi valitses kuningas Jarmerich 420. aastal, Hiärnil 351. aastal; kuningas Ingemar Brandisel 454. aastal ja Hiärnil 366. või 438. aastal, olenevalt allikatest. Lode-Werner toetub üldjuhul Brandisele, kuid siiski on teemavalikul erinevusi. Nii on Lode-Werner kirjeldanud Cassiodorusele toetudes, kuidas Eesti saadikud Preisimaalt viisid 6. sajandil gootide kuningale Theodericule Itaaliasse merevaiku. ${ }^{68}$

Perioodi kirjelduse lõpu võiks dateerida aastaga 1075, kui Knut Püha olevat Eestimaa vallutanud ja muutnud selle Taani hertsogiriigiks. Liivimaa, Lätimaa, Kuramaa ja Preisimaa jäid vabaks kuni 1158. aastani, mil

66 Brandis, Chronik, 44; Hiärn, Ehst-, Lyf- und Lettlaendische Geschichte, 56. Oli oluline, et Starkotter on pärit Rootsist, sest teda käsitleti kui kohalikku Heraklest, vt Lindroth, Svensk Lärdomshistoria. Stormaktstiden, 251.

67 Kelch, Liivimaa ajalugu, 32. Küsimus võib seisneda ka selles, kas Kelch usaldas pigem Saxo Grammaticust või Johannes Magnust.

68 Lode's Ehst- und Livländische Geschichte, EAA, f. 2062, n. 1, s. 6, 1. 47p-48. 
tulid saksa kaupmehed. Sellisele käsitlusele loob aluse Moritz Brandis (toetudes Albert Krantzile, Saxo Grammaticusele ja Johannes Magnusele) ning tõendab seda Tallinna Mihkli kloostri privileegidega, mida ta ise on käes hoidnud ja pikalt kirjeldab. ${ }^{69}$ Kõige suuremat tähelepanu osutab asjaolule Lode-Werner, kes kirjeldab eraldi ka edasist Eestimaa hertsogiriigi ajalugu ning osaliselt selle alusel eristab oma töös Eestimaa ajaloo Liivimaa, Lätimaa ja Semgale ajaloost, mis on Balti vanemas ajalookirjutuses erandlik nähtus, sest enamasti kirjeldatakse piirkonna ajalugu koos. ${ }^{70}$ Thomas Hiärn ei ole Eestimaa hertsogiriigis ega eriti Mihkli kloostri privileegides veendunud, Christian Kelch justkui on. Siinkohal tuleb huviga märkida, et Moritz Brandise kroonika on hilisematele suurem autoriteet kui pisut allikakriitilisem Thomas Hiärn. Kumbki pole aadlisoost ning kumbki kroonika ei olnud trükitud, seega vajavad Moritz Brandise kroonika autoriteetsuse tagamaad kindlasti edasist analüüsi.

Kui võrrelda varasemat Johann Renneri teksti Moritz Brandise käsitlusega, siis võib tõdeda, et üldiselt on kujutatud samu sündmusi. Renner alustab oma käsitlust hiljem ning tema kirjeldused ei ole nii detailsed. Et asetada siinsed sündmused üle-Euroopalisse konteksti, lisab Renner aeg-ajalt märkuseid selle kohta, kes samal ajal Kreekas või Roomas valitses. Võrreldes 17. sajandi kroonikutega, on Renner põhiliselt kirjeldanud vaid Taani valitsejate suhteid Baltikumiga, me ei leia rootslaste ja gootide valitsejaid. Võimalik, et Renner ei tundnud Johannes Magnuse teost, mis sajandi keskel Roomas välja anti.

Moritz Brandise tekst oli tuntud kõikidele järgnevatele artiklis käsitletud kroonikutele, mistõttu võiks eeldada, et nad võtsid perioodi kirjeldamisel aluseks Brandise käsikirja. Rohkem või vähem on kõik Brandist ka silmas pidanud. Esialgse Brandise, Lode-Werneri, Hiärni ja Kelchi võrdluse tulemusena jäi mulje, et Hiärn koostas oma käsitluse Brandist silmas pidades, Lode-Werner järgis Brandist lühendatud kujul ja Kelch eriti lühendatud kujul, tuues ise sisse vaid Rimberti Püha Ansgariuse eluloo. Detailsem kroonikasündmuste ja kroonikate allikate analüüs näitas selle olevat tugevasti lihtsustatud. Tegelikult sõltus Hiärn Brandisest rohkem ja Lode-Werner ning Kelch vähem, kui esmapilgul võis arvata.

Kõige keerulisemaks osutus Brandise ja Hiärni teksti võrdlus. Nende tekstid on umbes sama mahukad ning kirjeldused enam-vähem sama

69 Brandis, Chronik, $39 \mathrm{jj}$.

70 Lode's Ehst- und Livländische Geschichte, EAA, f. 2062, n. 1, s. 6, 1. 48p jj. Seda traditsiooni jätkab Lode-Werneri kroonika Eestimaa osast kokkuvõtte teinud Adam Friedrich von Fischbach ning tema kokkuvõtet jätkab omakorda Otto Fabian von Wrangell. 
detailsed. Hiärni metodoloogia allikate tutvustamise ja kritiseerimise osas on algusest peale tugevam. Sündmuste kirjeldusi võrreldes näis siinkirjutajale, et Hiärni stiil on lihtsam ja konkreetsem. Brandise stiil on keerulisem ja vastavalt ajastu tavale paneb ta oma tegelaste (näiteks rootslaste ja gootide kuningas Berico, ${ }^{71}$ Kuramaa kuningas Dorno ${ }^{72}$ ) suhu pikki kõnesid. Kuigi ka Brandis on võimeline tooma lugejani kahe erineva allika teated. Nii dateerib ta Rootsi kuninga Germundi valitsusaja AC 378 nagu tema sõnul enamik ajaloolasi, mitte 23 aastat hilisemasse aega nagu Johannes Magnus seda teeb. ${ }^{73}$

Kuigi pistelisel võrdlusel leidus lõike, mis on Brandisega üsna sarnased, siis Hiärn ei ole sündmuste osas Brandist kindlasti rangelt jälginud. Ta on toonud teistele allikatele toetudes lisaks sisse mõned Brandise tekstis puuduvad valitsejad. Näiteks valitseb temal pärast kuningas Gapti mandri goote viimase poeg Hellmal, keda Brandis ei maini. Hiärn on sellise valitseja avastanud Hans Strelowi Ojamaa kroonikast. ${ }^{74}$ Mõned valitsejad on Hiärn aga vahele jätnud. Nii ei pidanud ta gootide kuningaid Balthust ja Godarichi piisavalt oluliseks, et neid oma kroonikas mainida. ${ }^{75} \mathrm{Ka}$ valitsejate järjekord võis olla erinev.

Lode-Werneri kroonika on tugevasti Brandisest mõjutatud. Kohati on Brandist praktiliselt tsiteeritud, vahetades ära vaid mõned üksikud sõnad, kuid päris palju Brandise teksti jõuab Lode-Werneri kroonikasse lühendatud kujul. Kohati tundub, et Lode-Werner tahaks Brandise teksti meelega ümber öelda. Lode-Werneri kroonikas on viiteid mitmetele autoritele, kellele Brandis ei ole viidanud, teiste allikate toel on lisandunud mõned valitsejad. Näiteks Kuramaa kuninga Lockeri nimi Lode-Werneril esineb, Brandisel aga mitte. ${ }^{76}$

Kelchi kroonika võrdlemise varasemate käsitlustega teeb keerulisemaks see, et selle tekst on väga lühike. Kelch on sündmusi kajastanud väga kokkuvõtvalt ning seega ei ole võimalik võrrelda konkreetseid lauseid eelnevate tekstidega. Tuleb siiski nõustuda kroonika tõlkija Ivar Leimusega, et suuresti toetub Kelch Brandise käsitlustele. Samas on kroonikate tekstides

${ }^{71}$ Brandis, Chronik, 18-19. Pärineb ilmselt Johannes Magnuse kroonikast Gothorum Sueonumque Historia (Romae, 1558).

72 Brandis, Chronik, 25-26. Pärineb Saxo Grammaticuselt, vt Saxo Grammaticus, The history of the Danes, I-IX, ed. by Hilda Ellis Davidson; trans. by Peter Fisher (Woodbridge, Rochester, 2006).

73 Brandis, Chronik, 35

74 Ibid., 20; Hiärn, Ehst-, Lyf- und Lettlaendische Geschichte, 51.

75 Brandis, Chronik, 22; Hiärn, Ehst-, Lyf- und Lettlaendische Geschichte, 51.

76 Lode's Ehst- und Livländische Geschichte, EAA, f. 2062, n. 1, s. 6, 1. 4op; Brandis, Chronik, 24. 
ka mõned erinevused. Üks on näiteks Taani kuningas Frotho valitsusaja kirjeldus, mida ei ole ei Leimus ega allakirjutanu suutnud ühegi allikaga otseselt seostada. ${ }^{77}$ Teine Brandisest erinev käsitlus on Rootsi kuningas Olofi ja kuramaalaste vaheline konflikt, mille Kelch on leidnud Rimberti Püha Ansgariuse eluloost. ${ }^{78}$

Ühe 16. sajandi ja nelja 17. sajandi krooniku võrdluse analüüsi tulemusena võib tõdeda, et Balti ajalookirjutuses oli välja kujunenud käsitlus varakeskajast, milles mängisid suurt rolli erinevad Skandinaavia valitsejad. Sellise käsitluse autoriks ei olnud Moritz Brandis, kelle töö kõik hilisemad kroonikud hoolikalt ümber kirjutasid, vaid tema allikad. Hilisematel autoritel oli Brandise tekst ilmselt ees, kuid nad konsulteerisid teiste allikatega või läksid otse Brandise allikate juurde.

Varauusaegses Euroopas oli sellisel ajalookäsitlusel teatav poliitiline varjund, kuid kas sama on võimalik tuvastada ka Balti ajalookirjutuses? Ajalookirjutusest oli juba 16. sajandil saanud ka Eesti- ja Liivimaal propagandavahend. Erinevate teostega kaitsti nii oma privileege, patroone kui ka usku. ${ }^{79}$ Artikli alguses toodud kriitika kroonikute suhtes sidus Brandise Rootsi ülemvõimuga, Lode-Werneri aga Taani-meelsusega. Kahtlemata seotakse kroonikates piirkond tihedasti Skandinaavia riikidega ning see sobis hästi 17. sajandil valitsenud Rootsi võimudele. Samas on raske öelda, millisele positsioonile asetusid kroonikud Rootsi ja Taani vahelises võitluses, või väita, et eelpoolmainitud eeldatav seotus kahe erineva Skandinaavia võimuga oleks muutnud Brandise ja Lode-Werneri käsitlused üksteisest nähtavalt erinevaks. ${ }^{80}$ Ühest küljest alustavad 17. sajandi kroonikud kõik Rootsi valitsejatest, kelle Johannes Magnus Taani kuningatest vanemaks kirjutas. Ent oli siin tegemist poliitilise seisukohavõtuga või pigem sellega, et Johannes Magnuse Rootsi kuningad puutusid kronoloogiliselt Balti rahvastega varem kokku kui Saxo Grammaticuse Taani kuningad? Arvestades asjaolu, et gootitsismi elemendid (kui Renner välja arvata) esinesid Rootsi suurvõimu aegses Balti ajalookirjutuses üsna selgelt ning põhiliselt Eestimaal või siis Rootsi ülikoolis Tartus, ei saa kirjelduste poliitilist aspekti pidada tähtsusetuks. Samas võib siinkohal küsida, millistel motiividel liitis müütilise esiajaloo oma kroonika algusesse Johann Renner.

\footnotetext{
77 Kelch, Liivimaa ajalugu, 31.

78 Ibid., 33-34.

79 Katri Raik, “Ajalookirjutuse kõrgaeg Eesti- ja Liivimaal”, Ajalooline Ajakiri, 4 (2001), 5-26 (20-25).

80 Siinkirjutaja hinnangul ei ole Lode-Werneri kroonika niivõrd Taani-, kuivõrd Eestimaa-meelne ja autori motiiv võis pigem olla soov viia Eestimaa 13.-14. sajandi ajalugu võimalikult eraldiseisvaks Liivimaa 16.-17. sajandi ajaloost.
} 


\section{Kroonikute allikatest}

Varakeskaja kirjelduse näol ei ole tegemist Eestimaa ja Liivimaa ajalookirjutajate oma fantaasiaga, vaid kogu tekst on kompileeritud erinevate allikate põhjal. Kohati on allikaid mainitud nimeliselt, kohati üldistatult, näiteks norra autorid, vene autorid, isegi inglise autorid. Allikate hulgas eristuvad teosed, mida on kasutatud rohkem, ning need, mida on kasutatud ilmselt vaid mõnes üksikus kohas, kus tahetakse esile tuua mõni konkureeriv arvamus, nimekuju, aastaarv või lisada midagi, mis põhiallikas on puudu. 17. sajandi ajalookirjutuse juures ei saa kunagi rõhutamata jätta, et allika nimetamine ei tähenda seda, et kroonik oleks teost ise käes hoidnud. On võimalik, et nimetatud autorit on kasutatud läbi kellegi hilisema teose. Paraku oli selle kindlaks tegemine antud artikli kontekstis liialt töömahukas. Mõningate allikatega on kroonikatekste siiski pisteliselt võrreldud.

Johann Renneri allikad on Hausmanni ja Höhlbaumi väljaandes esitatud lehe äärtel. Sealt võime leida Achilles Pirminius Gassaruse (1505-77) "Historiarum et chronicarum mundi epitome velut index", Saxo Grammaticuse ja Albert Krantzi (1448-1517) teosed. Gassaruselt näib Renner olevat võtnud maailma ajalugu puudutavaid fakte. Näiteks seda, et samal ajal kui Taanis valitses kuningas Hading, tuli Pärsia valitseja Xerxes miljoni mehega Kreekasse. Saxo Grammaticuse "Gesta Danorum" (trükitud 1514) on olnud tema põhiallikas ning Krantzilt on ta kasutanud nii teost "Wandalia" (1519) kui ka "Chronica regnorum aquilonarium Daniae, Suetiae et Norvagiae" (1546).

Moritz Brandise põhiallikateks võib pidada Johannes Magnuse (14881544), Albert Krantzi ja Saxo Grammaticuse teoseid. Lisaks on ta nimetanud ka Jacob Gislonise raamatut "Chronologia Magna" ning 6. sajandist pärit Jordanest, kes kirjutas gootide ajaloo. Renneri ja Brandise sisuline erinevus seisnes üsna palju selles, et Renner ei olnud kasutanud Johannes Magnuse teost, millest pärinevad paljud rootslaste ja gootide valitsejad, keda Renner ei maini.

Lode-Werneri kroonikast leiab lisaks Brandise poolt mainitutele autoritele veel antiikkirjanikud Tacituse ja Ptolemaiose ning 6. sajandist pärineva Rooma kirjaniku ja riigimehe Cassiodoruse. Cassiodorus kirjutas gootide ajaloo, mis on säilinud läbi Jordanese kirjutise. Ääremärkusena on nimetatud ka Hans Nielsen Strelowi (1587-1656) Ojamaa kroonikat, mis ilmus 1633. aastal. Saksa ajaloolast Johannes Micraeliust (1597-1658) nimetatakse kroonikas paar korda seoses gootide ajalooga. Taani ajaloolastest on mainitud ka Arild Huitfeldi (1546-1609). 
Kõige rohkem erinevaid allikaid on ära märkinud Thomas Hiärn ning tema allikaline baas on kõige vaheldusrikkam. Ka tema tunneb Strelowi, Huitfeldi ja Micraeliust. Paar korda on Hiärn maininud taani kronoloogi Swaningiust. Kroonik on ilmselt mõelnud Svaning nooremat ehk Hans Jensen Svaningit (1600-76). Hans Svaning vanem (1503-84) oli Taani kuninglik ajalookirjutaja, kes kirjutas Taani ajaloo, mis jäi käsikirja ning hävis tulekahjus. Tema tütrepoeg Hans Jensen oli vaimulik ja ajalookirjutaja. Temalt ilmus mitu kronoloogiat puudutavat teost, millistest olulisim on 1650. aastal ilmunud "Chronologia Danica". Keskaegsetest allikatest nimetab Hiärn ka Bossau Helmoldit, kes kirjutas kroonika slaavlaste ajaloost, ning Bremeni Adamat. Skandinaavia autoritest tundis Hiärn Rootsi kroonikut Ericus Olaid (u 1420-86), Taani kuninglikku ajalookirjutajat Johann Isaac Pontanust (1571-1639) ning Olof Vereliuse välja antud "Hervarar saagat”. Jordanese teose kõrval tundis Hiärn ka tema kaasaegset Procopiust.

Nii Thomas Hiärn kui Christian Kelch on maininud ja ilmselt ka kasutanud Bremeni-Hamburgi peapiiskop Rimberti kirjutatud Püha Ansgariuse elulugu. Kelch näib olevat teosele või siis samas kohas viidatud Clas Örnhiälmi (1627-95) Rootsi kirikuloole rohkem tähelepanu pööranud ja nii toob ära tingimused, mille alusel kuramaalased Rootsi võimu alla läksid. ${ }^{81}$

Kui võrrelda kroonikute kolme põhiallika tekste kroonikatekstidega, siis Johannes Magnus alustab Rootsi valitsejate kronoloogiat esimesest valitsejast kuningas Magogist. Esimene kuningas, kes ka siinsetel kroonikutel jutuks tuleb, on viies Siggo, kes rajas Sigtuna linna. Järgmisena mainitakse 14. kuningat Bericot. Siit näivad kõik kroonikud olevat Johannes Magnusega ühel nõul, et Saksamaa gootide valitsejaks saab Gapt. Seejärel toetavad Brandis, Lode-Werner ja Kelch Magnust, kes järgmise valitsejana nimetab Augise, kuid Hiärn järgib Strelowi ning toob siia vahele kuningas Hellmali, ning alles tema järel poja Augise. Üldjuhul Johannes Magnust sõna-sõnalt ei järgita ning näib, et ka Magnuse poolt nimetatud valitsejate puhul võis olla nii Brandise kui ka hilisemate kroonikute käsutuses paralleelselt ka mõni teine teos aastaarvude ja erinevate nimekujudega.

Saxo Grammaticuse teosest jätavad kroonikud vahele Taani riigi alguse, kuningas Grami seiklused naistega, võlurid ja muu üleloomuliku või ebaolulise. Võlurid, draakonid, hiiglased ja koletised, keda võib leida peaaegu igast Saxo esimestest raamatutest, ei ole sealtkaudu Balti ajalookirjutusse edasi liikunud. Keskendutud on nendele sündmustele, millel oli kasvõi kaugem seos siinse piirkonnaga.

${ }_{81}$ Kelch, Liivimaa ajalugu, 33-34. 
Jordanese $^{82}$ puhul tundub, et see ei olnud esmane allikas nagu Saxo, vaid et kroonikud pigem kasutavad Jordanest läbi Johannes Magnuse. Jordanes on väga hüpliku tekstiga, tal on Skandinaavia sündmused segamini Kreekas toimuvaga ja näib, et töö Jordanese gootide ja Skandinaavia lugude ühendamisel on ära teinud Johannes Magnus. Balti kroonikates tulevad gootide liikumine Skandinaavia poolsaarelt mandrile ning mandri gootide valitsejad käsitlusse sisse sama koha peal kui Magnusel. Võimalik, et Hiärn on pisut kasutanud Jordanest koos teiste autoritega, et luua selgust erinevate Euroopa muistsete rahvaste hulgas.

Kokkuvõttes võib tõdeda, et 17. sajandi Balti kroonikud järgivad alguses Johannes Magnust, kes on toetunud gootide ajaloo osas Jordanese käsitlusele. Pärast kuningas Philimeri on pigem silmas peetud Saxo Grammaticust ning sellest välja nopitud lõigud, millel on seos Liivimaa ajalooga. Taani kuninga Frotho seikluste lõpus (nagu märgib ka Paucker) on ilmselt liigutud jälle Johannes Magnuse raamatu juurde või on kasutatud mõlemat paralleelselt.

\section{Lõpetuseks}

17. sajandi Balti kroonikud üritasid kirjutada täispikki kroonikaid ning täitsid varakeskaega puudutava osa keskaegsete ja kaasaegsete autorite teoste toel. Kuigi mitte alati, on enamasti võimalik kindlaks teha ka krooniku allikad. Konkreetseid sündmusi või tegelasi, mis oleks kroonikute omalooming, ei julge siinkirjutaja küll välja tuua. Kroonikute "fantastika” pärines mitte nende endi sulest, vaid allikatest. Nii võib nõustuda Arthur B. Fergusoniga, et renessansiaegne ajalookirjutus ei suutnud veel legendil ja faktil vahet teha. Vanima aja osas oli nende ees tume ja segane ajalooperiood, mille mõistmiseks polnud nende metodoloogia veel piisav. Humanistide jaoks oli oluline toetuda kirjalikule autoriteedile kas siis antiikajast või pühakirjast. Probleem seisnes selles, et ka nende allikad olid täis legende vähemalt sama palju kui fakte. ${ }^{83}$

17. sajandi kroonikud on püüdnud ühendada erinevates allikates peituvat Baltikumi puudutavat informatsiooni. Autoritele tegi töö lihtsamaks see, et mõned nende varauusaegsetest eelkäijatest olid piirkonna sündmusi juba üritanud ühendada ja kasutanud keskaegseid kroonikaid (Saxo

\footnotetext{
82 Jordanes, The origin and deeds of the Goths, trans. by Charles C. Mierow (Princeton, 1908), The Project Gutenberg eBook, <http://www.gutenberg.org/files/14809/14809-8. txt> (6.12.2012).

83 Ferguson, "John Twyne", 26-27,
} 
Grammaticus ja Jordanes) oma varauusaegsete ajalooteoste kirjutamisel. Mõned autorid, eelkõige Moritz Brandis ja Thomas Hiärn, on lisanud ka sündmusi, mis ei puudutanud kohalikke rahvaid, samuti on Johann Renner aeg-ajalt oma teksti täiendanud informatsiooniga, kes kuskil maailmas samal ajal siinsete sündmustega valitses.

Nii allikate kui kirjanduse näol, mida Balti kroonikud kasutasid, oli tihti tegemist tolleaegsete autoriteetsete ja populaarsete teostega. Suhtumine allikatesse on kroonikute puhul erineval määral kriitiline, kuid siiski on ajalookirjutajad jätnud näiteks Saxo Grammaticuse kroonikast välja praktiliselt kõik, mis tundub ligilähedaselt fantastiline. Kuigi Euroopa kontekstis võib leida allikakriitilisemaid teosed, on käsitletud kroonikatega samaaegselt koostatud oluliselt kriitikavaesemaid üllitisi.

Kroonikates kirjeldati suhtlust Skandinaavia rahvaste ja Baltikumi rahvaste vahel varakeskajal, mille toimumist on raske eitada. Arturas Mickevičius ühendas oma uurimuses kirjalikud allikad (Saxo, Bremeni Adama, Henriku kroonika, Islandi saagad), ruunikirjad ja arheoloogilise materjali ning nentis, et suhted erinevate rahvaste vahel olid tihedad. Ta küll ei pea tõenäoliseks, et Balti hõimud oleksid olnud pikemaks ajaks Skandinaavia valitsejatele allutatud, pigem oli tegemist lühemate rüüsteretkede ja võib-olla mõjupiirkondadega. ${ }^{84}$ Seega olid Balti kroonikad ja nende allikad põhimõtteliselt õigel teel, kui nad leidsid, et varakeskajal toimus Baltikumi ja Skandinaavia vahel tihe liiklus. Niinimetatud "fantastika" tuleb sisse detailide osas.

Lisaks võib märkida, et arusaadavatel põhjustel on hilisem ajalookirjutus olnud kroonikute kujutatud müütilise esiajaloo osas väga kriitiline, kuid palju mõistvam Liivimaa avastamise legendi suhtes, mis on tekkinud ja laiemalt levinud paralleelselt gootitsismi traditsiooniga.

84 Arturas Mickevičius, Normanai ir baltai IX-XII A. (s.1., 2004), 161-165. Gootide küsimust ja arheoloogiat on uurinud ka Anders Kaliff, Gothic connections: contacts between eastern Scandinavia and southern Baltic coast 1000 BC-50o AD (Uppsala, 2001). Liiklust Balti regioonis viikingiajal ja varakeskajal (u 900-1150) on kirjalike allikate ja ruunikivide põhjal on oma doktoritöös vaadelnud ka Kristel Zilmer: 'He Drowned in Holmr's sea - His cargo-ship drifted to the sea-bottom, only three came out alive': records and representations of Baltic traffic in the Viking Age and the Early Middle Ages in early Nordic sources (Tartu ülikool, 2005). 


\section{ABSTRACT: Gothicism in early modern Baltic historiography}

The purpose of this article is to describe and analyze the seventeenthcentury view of early medieval history. It is based on four Baltic chronicles: those of Moritz Brandis, Thomas Hiärn, Gustav von Lode and David Werner, and Christian Kelch. In addition, a sixteenth-century chronicle by Johann Renner was added as an independent text, since it was unknown to the four chroniclers mentioned above.

The subject has found little attention in Baltic German and contemporary Estonian historiography, but could be studied as an interesting phenomenon in early modern historiography in the context of developments in Europe at the same time.

The first part of the article gives examples of the origin myths of England and France and proceeds to give a short overview of the history of the Gothicism in Swedish historiography. The second part summarizes the description of early medieval history of the chronicles, compares the texts, and searches for the sources and motives of the chroniclers.

The chronicles describe centuries full of military campaigns between Scandinavian and Baltic tribes and their rulers. It seems that Moritz Brandis was the base text for the later chroniclers, though his text was not copied word-for-word. The chronicles of Lode-Werner and Kelch followed Brandis's text more closely than Hiärn. Brandis and Hiärn had lengthier and more detailed descriptions of events, while the texts of Lode-Werner and especially Kelch were shorter and much less detailed. However, they both added events or episodes (from their sources) that are not included in the chronicles of Brandis and Hiärn. All four storylines follow a similar path, but each has slight differences. However, it was not Moritz Brandis who created (as in made up) the early modern view of the Baltic early medieval past, partly because at the end of the sixteenth century Johann Renner also constructed a similar view of early medieval history. Brandis was the base text, but Hiärn probably wrote quite an independent narrative based on Brandis's sources.

The practice of writing mythical or legendary history for European nations was quite common in the early modern period and had its roots in both politics and the lack of criticism toward ancient and medieval sources. The high tide of Gothicism in the kingdom of Sweden coincided with the Swedish rule in Estland and later Livland. The political aspects are also important in the Baltic context but should not be overemphasized. Although Gothic historiography was more widespread in the province of 
Estland, which had been under Swedish rule longer than the province of Livland, and at the Swedish university of Tartu, both competing Danish and Swedish sources were used. It seems more likely that the chroniclers wanted to go back as far as their sources allowed, which is why they included the Goths, Swedes, and Danes. The chroniclers did not create the past; they compiled it from their sources, which were both popular and authoritative at the time, such as the medieval chronicle of Saxo Grammaticus and the work of Johannes Magnus.

The Baltic chroniclers were interested in sources that described the events concerning the Baltic area, and they left out events they considered supernatural or otherwise unimportant. They did not invent events or mythical ruler dynasties for the local tribes, although one or two local rulers were mentioned. If anything, they were rather unimaginative, and Thomas Hiärn and Lode-Werner were outright skeptical of the mythical early medieval past.

KEYwORDs: Gothicism, chronicle, historiography, early modern, Estonia, Livonia.

JANET Laidla (b. 1982), is a Lecturer of Estonian history at the Institute of History and Archaeology, University of Tartu. ${ }^{\star}$

* Correspondence: Institute of History and Archaeology, University of Tartu, Ülikooli 18, 5009o Tartu, Estonia. E-mail: Janet.Laidla@ut.ee 